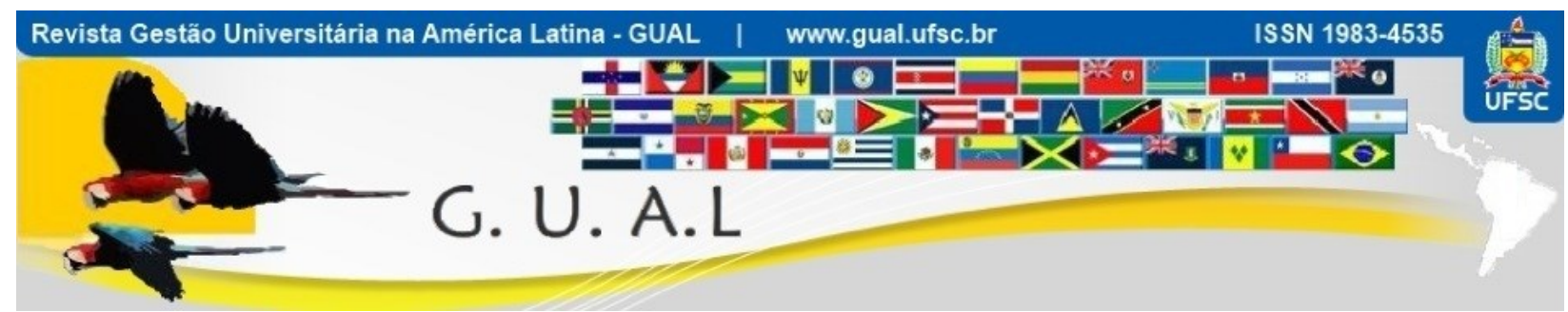

DOI: http://dx.doi.org/10.5007/1983-4535.2017v10n3p163

\title{
CONSTRUINDO UM AVIÃO EM PLENO VOO: A INFLUÊNCIA DO CONFORTO FÍSICO NO CLIMA ORGANIZACIONAL DE UMA INSTITUIÇÃO FEDERAL DE ENSINO SUPERIOR
}

\section{BUILDING AN AIRPLANE IN FULL FLIGHT: THE INFLUENCE OF PHYSICAL COMFORT IN THE ORGANIZATIONAL CLIMATE OF A PUBLIC HIGHER EDUCATION INSTITUTION WITH ITS FACILITIES IN CONSTRUCTION}

Denise Gutierrez Castro, Mestre Universidade Federal do ABC - UFABC denisegcastro@gmail.com

Fernando Thiago, Doutor Universidade do Estado do Mato Grosso - UNEMAT admfernandoth@gmail.com

Eduardo de Camargo Oliva, Doutor Universidade Municipal de São Caetano do Sul - USCS eduardo.oliva@uscs.edu.br

Edson Keyso de Miranda Kubo, Doutor Universidade Municipal de São Caetano do Sul - USCS edson.mk@gmail.com

Wilson José de Souza, Mestre Universidade Municipal de São Caetano do Sul - USCS wilson.wjs@terra.com.br

Recebido em 09/novembro/2015

Aprovado em 19/maio/2017

Sistema de Avaliação: Double Blind Review 


\title{
RESUMO
}

Impulsionadas pelo programa brasileiro de Reestruturação e Expansão das Universidades Federais (REUNI), as universidades federais brasileiras têm apresentado franca expansão. Com isso, em algumas unidades, os servidores realizam suas atividades em um ambiente de trabalho com instalações físicas inacabadas e em construção. Considerando que o conforto físico é uma das dimensões do clima organizacional, este artigo tem como objetivo abordar a forma como o ambiente físico influencia a formação da construção do clima organizacional. Para tanto, utilizou-se uma abordagem qualitativa por meio do método exploratório. Os dados foram coletados a partir dos registros de discussões em grupo pela observação participante. Do ponto de vista da ergonomia, os funcionários desta instituição são muito afetados em função do prédio estar em construção. Os problemas apontados foram: ruídos altos, problemas de higiene e limpeza, insegurança e tremores na estrutura física. Verificou-se que os trabalhadores demonstram insegurança e preocupação com essas situações em seu ambiente de trabalho que, consequentemente, afetam a dimensão conforto físico referente ao clima organizacional. Contudo, observou-se que, mesmo diante das dificuldades avaliadas, os servidores acabam por não deixar de desempenhar suas funções.

Palavras chave: Conforto físico, Clima organizacional, Universidade Brasileira.

\begin{abstract}
Driven by the Brazilian program Restructuring and Expansion of Federal Universities Brazilian, the federal universities are placed in a setting that has booming,. With that in some units the servers perform their activities on your desktop with unfinished physical facilities and construction. Whereas the physical comfort is one of the dimensions of organizational climate, this article aims to address how the physical environment influences the formation of the organizational climate construction. Therefore, this article is presented with a qualitative approach to measure the phenomenon, obtained through an exploratory research. Data were collected from the records of group discussions through participant observation. The ergonomics point of view, the employees of this institution are greatly affected due to the building being under construction. The problems mentioned were: loud noises, problems of hygiene and cleanliness, insecurity and tremors in the physical structure. It was found that the workers demonstrated insecurity and concern for these work situations that consequently affect the physical comfort, one of the organizational climate factors. However, it was observed that even with the difficulties evaluated, servers end up not fail to perform their duties.
\end{abstract}

Keywords: Physical comfort, Organizational climate, Brazilian university. 


\section{INTRODUÇÃO}

O tema desta pesquisa remete-se a ideia da construção de um avião em pleno voo, trata-se de uma analogia aos tempos modernos, na qual a sociedade está exposta a uma série de desafios, que impõe dinamismo e tomada de decisão em meio a ambientes em constantes mudanças, especialmente ocasionadas por pressões que a atual competitividade acirrada produz nas organizações. Essas mudanças nem sempre são definidas a partir de um planejamento eficientemente desenvolvido, gerando nas pessoas uma visão e um conjunto de sensações e percepções sobre um grupo de tarefas e atividades inseridas neste cenário. As alterações, sem planejamento adequado, podem gerar deficiências ou anomalias no ambiente de trabalho e refletir no desempenho da organização.

Nesse sentido, os principais problemas causados aos trabalhadores geram impacto no clima organizacional, considerado uma das áreas da gestão de pessoas relevantes ao desempenho organizacional (Schneider, Ehrhart \& Macey, 2012). O clima organizacional é um instrumento capaz de encontrar deficiências na estrutura e anomalias no ambiente de trabalho. A amplitude dos resultados obtidos por meio do estudo do clima organizacional permite transmitir uma visão ampla da organização, possibilitando modificação nas atividades e planejamento, com vistas a influenciar os resultados da organização (Patterson, West, Shackleton, Dawson, Lawthom, Maitlis, Robinson \& Wallace (2005).

O clima organizacional é composto por diversos fatores/dimensões e o conforto físico constitui-se como um desses elementos (Campbell, Dunnette, Lawler e Weick, 1970; Sbragia, 1983; Colossi (1991); Rizzatti (2002); Bispo, 2006; Martins, 2008), analisado por esta pesquisa. Portanto, tem-se a possibilidade dessa dimensão refletir negativamente na percepção de insegurança pelos colaboradores pertencentes ao objeto desta pesquisa, o qual passou por um período de construção de sua estrutura física por estar em obras e em pleno funcionamento ao mesmo tempo.

Inseridas em um cenário de constantes transformações nos últimos anos, estão as universidades federais brasileiras, que apresentam franca expansão. Foram criadas 18 novas unidades e 321 campi, representando 117\% de ampliação desde 2003, o que demonstra que a educação superior está cada vez mais acessível aos mais diversos segmentos da sociedade (Brasil, 2014).

A Administração Universitária é uma área do conhecimento à parte da Administração de Empresas e da Administração Pública, com algumas particularidades. Isso significa que, da 
mesma forma como não se pode gerenciar órgãos públicos como se administra uma empresa privada, a administração universitária também tem suas formas distintas de gerenciamento (Rizzatti, 2002).

A Administração Universitária deve ser encarada como um ato pedagógico e não empresarial, preocupando-se com a problemática da gestão organizacional em instituições de ensino superior (Finger, 1993).

O Programa de Reestruturação e Expansão das Universidades Federais (REUNI) permitiu a expansão e a consolidação das unidades existentes e de novas unidades, sendo uma realidade nacional o fato de boa parte das universidades criadas ainda estarem com suas instalações físicas em construção e ao mesmo tempo executando suas atividades de ensino, pesquisa e extensão regularmente.

Neste contexto, um fator importante para o clima organizacional é o conforto físico. Este conceito, de acordo com (Martins, 2008), está relacionado às condições ambientais do trabalho de tal modo que assegure as um local seguro ao trabalhador.

O espaço de trabalho constitui aspectos ligados à exposição do indivíduo a agentes externos como higiene, ruído, ar, temperatura, umidade, luminosidade e equipamentos de trabalho. Desta forma, a higiene do trabalho é um elemento crítico na formação do clima organizacional, já que todos os colaboradores das universidades, tanto os técnicos administrativos como os docentes, assim como seu público-alvo (discentes), estão imersos em um ambiente em construção. Um melhor conhecimento do clima organizacional pode colaborar para a melhoria da qualidade de vida no trabalho, para otimização do desempenho das organizações e para o esclarecimento das relações entre esta e outras variáveis do comportamento organizacional (Martins, 2008).

O presente artigo tem por objetivo analisar os aspectos do conforto físico e sua influência no clima organizacional em uma universidade federal brasileira, que esteve em obras e ao mesmo tempo em pleno funcionamento. O problema a ser respondido é como o clima organizacional é afetado em uma organização em funcionamento com suas instalações físicas em obras?

Para o alcance do objetivo proposto, serão abordados os elementos teóricos sobre clima organizacional, mudanças e condições de trabalho, metodologia, resultados e considerações finais, contendo as indicações de possíveis trabalhos futuros.

\section{CLIMA ORGANIZACIONAL}




\section{CONSTRUINDO UM AVIÃO EM PLENO VOO: A INFLUÊNCIA DO CONFORTO FÍSICO NO CLIMA ORGANIZACIONAL DE UMA INSTITUIÇÃO FEDERAL DE ENSINO SUPERIOR \\ DOI: http://dx.doi.org/10.5007/1983-4535.2017v10n3p163}

O construto de clima organizacional é reconhecidamente um instrumento composto por diversas abordagens na área de Gestão de Pessoas, e tem sido amplamente utilizado como ferramenta de diagnóstico organizacional. São vários os modelos e conceitos a respeito do clima e sua relevância se deve ao fato de abordar o ambiente interno de trabalho. Nesse sentido, as influências do ambiente interno sobre o comportamento humano são inerentes aos estudos do clima organizacional, sendo importante determinar como as pessoas denotam seu ambiente de trabalho a partir dos estímulos proporcionados pela organização. Diante deste diagnóstico, torna-se possível intervir para se obter melhores condições de trabalho e desempenho a partir de um adequado clima organizacional.

Este construto contribui para moldar o comportamento dos indivíduos, por meio de procedimentos administrativos, participação nas decisões políticas e administrativas, recompensa e incentivos, e a influência aos fatores motivacionais dos integrantes da organização (Schein, 1996).

O clima organizacional tem sido conceituado, por exemplo, como "percepções compartilhadas que os membros desenvolvem através de suas relações com as políticas, as práticas e os procedimentos organizacionais tanto formais quanto informais" (Toro, 2001, p. 33). Para Koys e DeCotiis (1991, p. 266), trata-se de um "fenômeno perceptual duradouro, construído com base na experiência multidimensional e compartilhado pelos membros de uma unidade da organização, cuja função principal é orientar e regular os comportamentos individuais de acordo com os padrões determinados por ela”. Schneider e Reichers (1983) apresentam uma conceituação de clima como percepções compartilhadas dos funcionários sobre as práticas, procedimentos e eventos organizacionais, sendo essas percepções consideradas principalmente descritivas ao invés de avaliativas ou afetivas.

No estudo do clima organizacional captam-se as percepções dos empregados sobre a organização e seu ambiente de trabalho (Colossi, 1991). Dessa forma, busca-se revelar tanto o que eles pensam, quanto suas reações a respeito dos atributos específicos ou características da organização, que refletem seus valores e atitudes organizacionais (Rizzati, 1995). Não se busca captar apenas percepções individualizadas, mas sim apurar a percepção da coletividade, ou seja, conhecer o conjunto de percepções dos empregados em geral.

O estudo do clima é um excelente instrumento de feedback e de intervenção organizacional, que apresenta contribuições valiosas para o conhecimento e o manejo do funcionamento das organizações (Rizzati, 1995). 


\section{CONSTRUINDO UM AVIÃO EM PLENO VOO: A INFLUÊNCIA DO CONFORTO FÍSICO NO CLIMA ORGANIZACIONAL DE UMA INSTITUIÇÃO FEDERAL DE ENSINO SUPERIOR \\ DOI: http://dx.doi.org/10.5007/1983-4535.2017v10n3p163}

Vários modelos de clima organizacional possuem em suas dimensões e analisam a influência da estrutura ou o conforto físico como sendo fatores determinantes no estudo do clima. O modelo de estudo proposto por Martins (2008) define cinco dimensões de análise, quais sejam: apoio da chefia e da organização, recompensa, conforto físico, controle/pressão e coesão entre colegas.

Outro modelo criado por Sbragia (1983) é composto por 20 fatores: conformismo, estrutura, cooperação, recompensas, padrões, conflitos, identidade, estado de tensão, ênfase na participação, proximidade da supervisão, consideração humana, autonomia presente, prestígio obtido, tolerância existente, clareza percebida, justiça predominante, condições de progresso, apoio logístico proporcionado, reconhecimento proporcionado, forma de controle.

O modelo desenvolvido por (Colossi, 1991) tem como finalidade analisar o clima organizacional pelos seguintes fatores: filosofia e ambiente geral na empresa; condições físicas de trabalho; sistema de avaliação e controle; treinamento e desenvolvimento profissional; progresso funcional; comportamento das chefias; satisfação pessoal; sistema de assistência e benefício; lazer e relacionamento sindical.

Em estudos realizados em instituições públicas educacionais e universidades brasileiras, Rizzatti (2002) e Colossi (1991) estabeleceram os seguintes fatores de clima organizacional: imagem institucional, política de Recursos Humanos, sistema de assistência e benefícios, estrutura organizacional, organização e condições de trabalho, relacionamento interpessoal, comportamento das chefias, satisfação pessoal, planejamento institucional, processo decisório, autonomia universitária e avaliação institucional.

Diretamente ligado a esta pesquisa e presente em boa parte dos modelos de estudo do clima organizacional está o conforto físico. Este se refere ao ambiente físico, segurança e conforto proporcionados pela organização aos empregados. O ambiente físico, por exemplo, deve receber uma atenção especial por parte dos gestores, pois é o local onde os colaboradores permanecem quando estão realizando suas tarefas e por isso a importância que este seja agradável, de forma a estimular um bom trabalho.

A organização deve se concentrar na criação de condições que facilitem um alto nível de rendimento durante um longo período de tempo e também permitir a cada colaborador, através da associatividade e do trabalho na organização, o atendimento de algumas de suas necessidades mais importantes. 


\section{CONSTRUINDO UM AVIÃO EM PLENO VOO: A INFLUÊNCIA DO CONFORTO FÍSICO NO CLIMA ORGANIZACIONAL DE UMA INSTITUIÇÃO FEDERAL DE ENSINO SUPERIOR \\ DOI: http://dx.doi.org/10.5007/1983-4535.2017v10n3p163}

A questão ergonômica é um tema importante para se estudar nas organizações quando se busca entender a influência do conforto físico nas condições de trabalho. Questões como luminosidade, ruído, temperatura, estresse e lesão por esforço repetitivo são relevantes nas organizações.

As instituições necessitam fornecer condições de trabalho para seus empregados e estabelecer indicadores de coordenação das atividades, esperando como retorno a eficiência nos serviços executados e observando aspectos de condições ergonômicas (Hall, 2004).

A natureza global do clima sugere, portanto, que o conceito seja multidimensional e inerente ao contexto que está inserido, sendo fundamental estudar seus fatores organizacionais (Thumim \& Thumim, 2011; Schneider, Ehrhart \& Macey, 2012; Bernstrøm, Lone, Bjørkli, Ulleberg \& Hoff, 2013), especialmente quando esta passa por mudanças em sua estrutura física e organizacional.

\subsection{MUDANÇAS E CONDIÇÕES DE TRABALHO}

Com as transformações do mundo empresarial, mudanças passam a fazer parte do cotidiano dos trabalhadores. Diante disso, as mudanças podem representar ameaças aos status de trabalho, gerar sobrecarga e riscos físicos inerentes às atividades desenvolvidas, desta maneira, o processo de precarização do trabalho (ou mesmo o fim deste) pode produzir tensão e medo (Cunha \& Mazzilli, 2005).

A Nova Gestão Pública busca o aumento da eficiência, eficácia e melhoria da qualidade dos serviços públicos. Se antes prevalecia a conformidade a processos burocráticos e rotineiros, bastando conhecer as regras e as leis para cumprir as tarefas, atualmente as demandas se modificaram. A perspectiva burocrática tem dado espaço para uma abordagem que credita ao Estado não apenas instrumentos que garantam sua propriedade e seus contratos, mas também que a formulação e aplicação de políticas públicas estratégicas para sociedade. Nas experiências conhecidas (Inglaterra, EUA, Brasil, entre outras) isto significou diversas mudanças organizacionais, tais como: enxugamento do quadro de pessoal, flexibilização dos contratos de trabalho, terceirizações e privatizações (Cunha \& Mazzilli, 2005; Rodrigues \& Gondim, 2013).

A relação entre a organização pública e a sociedade está mudando. Neste período de transição novos valores, crenças, estruturas políticas tem apresentado impacto na sociedade. As alterações provocam insegurança, que são manifestadas emocionalmente e precisam ser 
administradas. Por isso, a necessidade de entender melhor como se manifestam as emoções no contexto das organizações públicas (Cunha \& Mazzilli, 2005; Rodrigues \& Gondim, 2013).

Na pesquisa de Rodrigues e Gondim (2013), foi verificada a manifestação de emoções negativas frente a mudanças no contexto organizacional, e constatou-se o predomínio da raiva, sendo o medo a emoção menos sentida. Diante desse resultado, pode-se perceber um descontentamento dos servidores quanto ao trabalho que executam. Pode-se pensar que esta manifestação tenha relação com a estabilidade de emprego, que pode levar a processos de acomodação e estagnação (Rodrigues \& Gondim, 2013). Contudo, as organizações estudadas não estavam passando obras em suas instalações físicas e o pleno funcionamento de suas atividades, desta forma, trata-se de um fenômeno diferente do proposto por este artigo.

As mudanças, no contexto da educação superior brasileira, podem ser observadas pela pressão por melhorar seus índices de desempenho nacional, como o caso em estudo, com esforços para melhorar o acesso à educação superior gratuita, e consequentemente melhorar as condições sociais.

No Brasil, esta expansão faz parte do Programa de Reestruturação e Expansão das Universidades Federais, que amplia a oferta de vagas na Educação Superior com a instalação de novas unidades desde o ano de 2003 (Brasil, 2014), algumas mesmo já em funcionamento, ainda estão com suas estruturas físicas em fase de acabamento.

Tais organizações passam por mudanças, que proporcionam principalmente resistência por parte das pessoas. Neste aspecto Stoner (1985) apresenta três fontes gerais de resistência à mudança. Quando existe um grau elevado de incerteza quanto às causas e efeitos da mudança. Quando falta disposição para abrir mão de benefícios existentes. E quando as pessoas têm consciência da fraqueza das mudanças propostas. Neste último caso, as pessoas da organização resistem à mudança porque têm conhecimento de problemas potenciais que foram possivelmente desconsiderados pelos agentes das mudanças.

As incertezas causadas por este cenário e as novas implementações de estruturas físicas, quando não bem planejadas, causam insegurança e afetam as condições de trabalho.

Neste ponto, as condições de trabalho estão relacionadas com o posto de trabalho, seu ambiente físico, que inclui principalmente temperatura e ruído. Este conceito é definido como qualquer aspecto circunstancial em que se produzem as atividades de trabalho, considerando tanto os fatores do entorno físico em que o trabalho se realiza, quanto às circunstâncias 


\section{CONSTRUINDO UM AVIÃO EM PLENO VOO: A INFLUÊNCIA DO CONFORTO FÍSICO NO CLIMA ORGANIZACIONAL DE UMA INSTITUIÇÃO FEDERAL DE ENSINO SUPERIOR \\ DOI: http://dx.doi.org/10.5007/1983-4535.2017v10n3p163}

temporais em que se dá e as condições sobre as quais os trabalhadores desempenham seu trabalho (Ramos, Peiró \& Ripoll, 2001).

As condições de trabalho são um conjunto de variáveis que definem a realização de uma tarefa concreta e o entorno na qual esta se realiza (Garrido, 2005).

Costa e Alves Filho (2013) relatam que nos estudos atuais sobre as condições de trabalho há notada relevância de trabalhos que abordam os aspectos como a relação com a satisfação no trabalho, higiene, segurança no trabalho e prevenção dos riscos laborais.

Hendrick (1993) considera que o processo evolutivo da ergonomia pode ser descrito em cinco etapas, de forma que todas são de fundamental importância, tanto para o indivíduo quanto para a organização. Uma dessas etapas está relacionada com a tecnologia da interface homem máquina, ou ergonomia ocupacional, a qual se preocupa com as questões físicas e de percepção aplicáveis a produtos, equipamentos e postos de trabalho.

Diante desses fatores e as formas de resistência, é bastante útil se a organização souber como trabalhar com essas pessoas (Stoner, 1985).

Desta maneira, os aspectos das relações de trabalho, tais como: inteligibilidade, transparência, visibilidade, exteriorização, confiança, solidariedade, reconhecimento, constituiriam as condições necessárias (mas não suficientes) para se estabelecerem as relações, destinadas a construir as barreiras coletivas contra o sofrimento (Dejours, 1998).

Contudo, as barreiras e o sofrimento causado pelas mudanças podem ser transformados em iniciativa e mobilização criativa, com a utilização da comunicação e de um espaço para discussão, onde as dificuldades e opiniões são públicas e possíveis de serem discutidas (Dejours, 1998).

As condições físicas em situações ruins podem gerar comprometimento pela dificuldade compartilhada e pelos desafios dos objetivos organizacionais traçados. Ainda segundo Dejours (1998), diante dessas dificuldades, surpreende-se pelo aparecimento de condutas contrárias ao individualismo, engajamento apaixonado, senso de responsabilidade, aplicação da criatividade.

No caso do serviço público, conforme apontado por Rodrigues e Gondim (2013), a estabilidade e o difícil acesso ao serviço público efetivo no Brasil permite uma valorização do emprego público conquistado pelos trabalhadores a ponto de suportar desconfortos e situações difíceis, geradoras de raiva e medo. 


\section{CONSTRUINDO UM AVIÃO EM PLENO VOO: A INFLUÊNCIA DO CONFORTO FÍSICO NO CLIMA ORGANIZACIONAL DE UMA INSTITUIÇÃO FEDERAL DE ENSINO SUPERIOR \\ DOI: http://dx.doi.org/10.5007/1983-4535.2017v10n3p163}

Cunha e Mazzilli (2005) ponderam que a participação dos trabalhadores em atividades injustas deriva de ações previamente calculadas, cujo objetivo é manter sua posição, conservar seu cargo, salário, vantagens, carreira, sendo necessário ter aceitação da situação e colaboração.

Os gestores dispõem de instrumentos de gestão para, apesar da adversidade, manter as atividades em funcionamento durante as ações disciplinadoras ou coercitivas, que são chamadas de sanção normalizadora, segundo Focault (1991), e são parecidas com o mecanismo penal. Nas organizações, funcionam como controle das atividades, das posturas e dos discursos.

Contudo, dentro dos processos comunicativos e das ações sociais entre as pessoas, são recriadas, a partir das adversidades e das normas estabelecidas, uma nova possibilidade de organização social no interior da ordem estabelecida (Cunha \& Mazzilli, 2005).

Diante do exposto, Koury (2002) afirma que em situações onde o medo é um elemento organizador dos grupos sociais, ocorrem reelaborações para sobrevivência, integração ou adequação aos modelos estabelecidos. No entanto, o medo pode estabelecer tanto a prática de aceitação das normas e regulação como também pode fundamentar a negação das imposições para um melhor ajustamento ou mesmo a sua superação.

\section{METODOLOGIA}

A pesquisa classificou-se como descritiva e de campo. A pesquisa descritiva tem como objetivo principal descrever as características de determinada população, fenômeno, ou o estabelecimento de uma relação entre dadas variáveis (Gil, 1996). Assim, esta foi usada para compreender a percepção dos colaboradores de uma instituição federal de ensino superior acerca do local de trabalho, cujas atividades são desempenhadas em um ambiente em obras. A pesquisa de campo, segundo Marconi e Lakatos (1996), é o tipo de pesquisa que pretende buscar a informação diretamente com a população pesquisada.

Os dados foram coletados a partir dos registros de discussões em grupo, com a participação de 15 servidores públicos efetivos, empossados nos cargos de docente e técnicoadministrativo. As informações foram obtidas por meio da observação participante. De acordo com Becker (1987), a principal característica da observação participante é a presença constante do observador nas tarefas do grupo ou organização pesquisada, pois, deste modo, ele consegue "ver as coisas de dentro" (Haguette, 1987). Portanto, o pesquisador adota duas 
funções: participa das atividades da organização ao mesmo tempo em que as observa (Godoy, 1995). Os dados obtidos foram registrados no período em que o prédio público estava sendo construído, o que consiste em um caso oportuno, visto ser uma situação rara para a investigação.

Assim, utilizou-se uma amostragem por acessibilidade de caráter não probabilístico, e de acordo com Costa Neto (1977), mesmo com a possibilidade de se obter dados com toda a população, selecionou-se uma amostra de uma parte que esteja acessível.

Por questões éticas de pesquisa, definiu-se por manter em sigilo os participantes da pesquisa, como também o nome da unidade federal de educação superior.

Os dados foram obtidos por meio digital, via fórum de discussão virtual, analisados pela técnica de Análise de Conteúdo e categorizados com enfoque na análise do discurso, estabelecendo uma versão moderna deste tipo de pesquisa e permitindo um enfoque interpretativo, mediado pelo contexto dos participantes da pesquisa. Para Hardy, Harley e Philips (2004), tanto a análise de conteúdo como a análise do discurso visam identificar a realidade social, contrapondo a análise de conteúdo tradicional, essencialmente funcionalista, baseado no método estabelecido por Bardin (2011), ao buscar o significado das comunicações a partir da codificação e quantificação. A análise do discurso permite compreender o desenvolvimento do significado e suas variações, de acordo com o desenrolar do tempo.

Ainda, de acordo com Hardy, Harley e Philips (2004, p. 20), “a versão moderna da análise do discurso possui sensibilidade, com relação ao uso das palavras e ao contexto no qual elas são utilizadas".

Com esta perspectiva, permitiu-se avaliar os termos emitidos pelos participantes da pesquisa, além da visão essencialmente funcionalista, de caráter quantitativo, onde fora considerado na análise todo o contexto envolvido pelas ocorrências administrativas, operacionais e de estrutura física observadas na situação analisada, complementado pela observação participante.

\section{ANÁLISE DOS RESULTADOS}

A Administração Universitária permeia suas atividades nos serviços administrativos e de infraestrutura (atividade meio) e a prática acadêmica que compreende laboratórios, prática de estágios, professor em sala de aula, etc. (atividade fim). Cada um desses setores da administração educacional constitui um campo específico de trabalho para o profissional da 


\section{CONSTRUINDO UM AVIÃO EM PLENO VOO: A INFLUÊNCIA DO CONFORTO FÍSICO NO CLIMA ORGANIZACIONAL DE UMA INSTITUIÇÃO FEDERAL DE ENSINO SUPERIOR \\ DOI: http://dx.doi.org/10.5007/1983-4535.2017v10n3p163}

instituição, cuja formação exige a aquisição de competências conceituais ou administrativas, técnicas e humanas, sendo que ambas devem caminhar juntas e não separadas, de acordo com Rizzatti (2002).

O programa de reestruturação das universidades brasileiras avança para o atendimento de demandas sociais reprimidas, ampliando a quantidade de unidades e vagas para o ensino superior. A vontade política e a necessidade social instigaram os agentes públicos a iniciarem os trabalhos em uma das unidades federais de educação superior mesmo sem sua estrutura predial estar completamente finalizada.

Do ponto de vista da prática gerencialista ou da Nova Gestão Pública, apoiado em Cunha e Mazzilli (2005) e Rodrigues e Gondim (2013), o governo brasileiro ao assumir a Educação Superior como macro política, mantém e amplia uma estrutura complexa, não permitindo processos de downsizing, terceirizações e privatizações, proporcionando eficiência e melhoria nos índices educacionais brasileiros. Vale ressaltar que é permitido pela Lei Federal n. 9394 (1990) a participação do setor privado no oferecimento de vagas no ensino superior. Por outro lado, em relação à gestão interna da universidade, a eficiência pode ter sido comprometida pelo mau planejamento durante a implantação da unidade, devido à não observância dos prazos e problemas para finalização das obras antes do início das atividades.

Um dos desafios dentro de um ambiente, cuja estrutura física está em construção, é gerenciar os problemas decorrentes da adequação ou adaptação dos locais de trabalho, falta de recursos mínimos como água e energia elétrica, sujeiras devido às atividades de engenharia civil, e as consequentes reações, desempenho, satisfação das pessoas em atividade.

$\mathrm{Na}$ instituição de ensino investigada, por estar em processo de construção, o ambiente físico é um dos elementos mais determinantes de seu clima organizacional (Martins, 2008; Rizzatti, 2002 e Colossi, 1991). Evidenciou-se que exercer as atividades laborais em prédios com suas instalações físicas em obras gera ruídos, tremores, insegurança, dentre outros, influenciando diretamente em diversos aspectos organizacionais, principalmente no clima organizacional.

Sob a ótica da ergonomia, os colaboradores desta instituição são bastante afetados em função das obras em seus campi. Nos dados coletados, foram constatados problemas de ruídos em função da obra, limpeza de seu ambiente de trabalho, insegurança e tremores. No trecho a seguir, o colaborador solicita esclarecimentos sobre tremores que estão sendo percebidos em seu ambiente de trabalho. 


\section{CONSTRUINDO UM AVIÃO EM PLENO VOO: A INFLUÊNCIA DO CONFORTO FÍSICO NO CLIMA ORGANIZACIONAL DE UMA INSTITUIÇÃO FEDERAL DE ENSINO SUPERIOR \\ DOI: http://dx.doi.org/10.5007/1983-4535.2017v10n3p163}

“Gostaria de saber se estruturas não serão afetadas pelas obras atualmente em curso que fazem todo o prédio tremer... Este fato se repete todos os dias há, pelo menos, duas semanas... Eu tenho um vídeo evidenciando a tremedeira" (Trabalhador 1, 2012).

Esta percepção foi compartilhada por demais membros, por exemplo:

“Gostaríamos de uma resposta profissional sobre os alegados tremores em virtude das obras e suas consequências com relação às estruturas... Ou vamos esperar para ver se o prédio cai e depois apurar as responsabilidades?" (Trabalhador 2, 2012).

De acordo com (Martins, 2008), um dos elementos para o entendimento sobre a influência do conforto físico para o clima organizacional é a avaliação do atendimento às necessidades físicas do trabalhador pelo ambiente de trabalho. Os seguintes relatos contribuem para esta análise, evidenciando que o conforto físico é prejudicado pelo ambiente em obras.

"Estamos há cinco dias com falta de água no campus e, até o presente momento, nenhum esclarecimento sobre o problema foi divulgado" (Trabalhador 3, 2012).

"Foram disponibilizados galões de água para beber, mas a situação nos banheiros é precária” (Trabalhador 4, 2012).

"O chão fica com muita poeira e areia, o que gera riscos de queda, a luz pisca o tempo todo, dificulta demais as aulas" (Trabalhador 2, 2012).

"Meus problemas respiratórios pioraram depois que iniciei minhas atividades neste prédio, tenho gastado com consultas médicas, porque não possuo plano de saúde e parte do meu salário está sendo gasto com medicação para minimizar os sintomas devido à grande quantidade de poeira no local de trabalho" (Trabalhador 5, 2012).

As declarações mostram a presença de tremores na estrutura física, perpetuando a insegurança aos colaboradores, além de não oferecer condições para atendimento das necessidades fisiológicas básicas como água, limpeza, banheiros limpos e em funcionamento, etc., impactando negativamente no clima organizacional.

Outro fator gerado pelo conforto físico é a percepção pelos colaboradores de que o ambiente de trabalho não possui espaço suficiente para a execução das atividades laborais, assim como de não ser um local arejado e com iluminação adequada (Martins, 2008). Os relatos obtidos a seguir evidenciam um primeiro diagnóstico institucional.

"A instituição foi ocupada antes da construção do prédio estar finalizada, esse é o maior problema. Quase todos os outros são decorrentes deste" (Trabalhador 3, 2012). 


\section{CONSTRUINDO UM AVIÃO EM PLENO VOO: A INFLUÊNCIA DO CONFORTO FÍSICO NO CLIMA ORGANIZACIONAL DE UMA INSTITUIÇÃO FEDERAL DE ENSINO SUPERIOR \\ DOI: http://dx.doi.org/10.5007/1983-4535.2017v10n3p163}

A instituição em estudo já apresenta elementos que demonstram o envolvimento dos membros da alta gestão para a proposição de soluções para a minimização dos problemas enfrentados, como relatado a seguir:

"Sei das inúmeras dificuldades pelo fato da instituição estar em implantação e em funcionamento ao mesmo tempo, mas temos que aproveitar construtivamente os desvios para que estes sejam corrigidos e sirvam para prevenção de possíveis próximos" (Trabalhador 6, 2013).

Todavia, o diálogo institucional apresentado é um canal de percepção dos sinais que retratam o clima organizacional. Estes, por mais abstrato que sejam se materializam no dia-adia. Trata-se de fatores relevantes para a gestão, possíveis de serem identificados por tais sinais, para que diversos efeitos decorrentes destes sejam evitados, tais como: desperdícios, alta rotatividade, enorme absenteísmo, greves, reclamatórias trabalhistas, conflitos e problemas de saúde (Luz, 2003).

Boa parte dos sinais detectados não fornecem elementos capazes de descobrir as causas, porém, servem como um alerta de que algo pode estar bem ou não. Fischer, Dutra e Amorim (2009) sugerem que os gestores utilizem uma ferramenta objetiva e segura para avaliar o clima organizacional, como, por exemplo, uma pesquisa estruturada de clima organizacional. Tais instituições, portanto, poderiam diante destes sinais, promover uma pesquisa.

Contudo, apesar dos elementos negativos referentes às más condições das estruturas básicas mencionadas pelos trabalhadores, verifica-se nas falas que estes, mesmo diante destas adversidades, realizam seus trabalhos, conforme apresentado na descrição abaixo.

"Os técnicos administrativos há muito tempo vem denunciando as péssimas condições de trabalho nesta instituição, sem qualidade de vida estamos adoecendo por desenvolver nossas tarefas em condições cada vez mais precárias. Estamos nos sacrificando para garantir o REUNI, ou seja, com as péssimas condições de trabalho que temos estamos garantindo a expansão tanto elogiada nacionalmente" (Trabalhador 7, 2013).

Um dos pontos que comprovam este elemento é a comunicação do grupo. Apesar de não haver elementos significativos que comprovam a eficiência da comunicação entre a gestão e trabalhadores, verificou-se que existe uma comunicação entre os trabalhadores. Nos termos de Dejours (1998), o canal de comunicação verificado transforma-se em um espaço de discussão, permitindo que as pessoas possam expressar seus descontentamentos e apoiar umas 
às outras na socialização de conhecimentos e atividades realizadas. Estas trocas de informações permitiram contornar os problemas denunciados, sendo uma das ferramentas essenciais para o enfrentamento das adversidades.

Em algumas descrições, os servidores acabam por utilizar recursos próprios ou internet das repúblicas vizinhas à universidade para realizar suas atividades de pesquisa e trabalho (Trabalhador 8, 2012). Ou quando alguns materiais não são instalados adequadamente, são readequados pelos próprios trabalhadores para que sejam efetivadas suas atividades (Trabalhador 3, 2012).

Neste sentido, os desafios frente às dificuldades supracitadas fazem com que os trabalhadores tenham condutas que superam as exigências mínimas de trabalho e procuram por soluções criativas, tendo engajamento apaixonado, conforme explicou Dejours (1998). Outra explicação para este fato encontra-se no trabalho de Rodrigues e Gondim (2013) e Cunha e Mazzilli (2005), onde a valorização social e econômica dos cargos ocupados pelos trabalhadores faz com que os mesmos suportem todas as situações difíceis e inseguras, mantendo seus cargos, posições, salários e outras vantagens decorrentes à ocupação do cargo.

Nos apontamentos de Koury (2002), o medo, ora pela insalubridade do ambiente físico, ora pela possibilidade de não exercer as atividades pertinentes ao cargo, foi um elemento organizador dos grupos da universidade, que permitiu a reelaboração das formas de trabalho, como visto nas adaptações ao prédio, readequação de ambientes, utilização de recursos externos. Tais reelaborações permitiram a continuidade, integração e adequação aos modelos estabelecidos, que pela força e comprometimento dos trabalhadores acabaram por serem atendidos.

\section{CONSIDERAÇÕES FINAIS}

As condições adequadas da estrutura física permitem influenciar na dimensão conforto físico do clima organizacional, essencial para o desempenho eficiente dos trabalhadores, uma vez que este tem reflexo no desempenho individual e organizacional, conforme abordado por Scheider, Ehrhart e Macey, (2012), Martins (2008) e Patterson et al. (2005).

$\mathrm{Na}$ instituição analisada, obteve-se a oportunidade de analisar um fenômeno de difícil manifestação, onde pessoas desempenham suas atividades em meio a prédios em plena construção e, portanto considerou-se esse fenômeno como raro, não localizado em outras pesquisas científicas, inclusive para fins de comparações dos resultados. 
Em relação ao método utilizado, a análise de conteúdo associada à análise do discurso permitiu-se avançar além da análise funcionalista recorrente por permitir trazer resultados ora não evidenciados diretamente nas argumentações dos participantes da pesquisa.

Com isso, os resultados levam a refletir que as dificuldades ocasionadas pelas obras em andamento causaram problemas como falta de água, iluminação, energia elétrica, desenvolvimento de trabalhos em locais não definitivos e adaptados, prejudicando o andamento das atividades, além de ter causado o sentimento de risco de vida devido aos tremores nos prédios relatados pelos trabalhadores.

Contudo, apesar dos problemas observados, os trabalhadores continuaram a desempenhar suas funções, mesmo em condições adversas, sugerindo, nos termos que Dejour (1998) que tais adversidades podem ter causado o comprometimento das pessoas para superar os desafios, a partir de um movimento social criativo nos espaços de discussões.

Para trabalhos futuros, sugere-se analisar como as relações do ambiente de trabalho nestas condições influenciam na saúde mental de seus colaboradores. Como exemplo, podem ser estudados neste contexto a Síndrome de Burnout, definida como um resultado do trabalho intenso sem a preocupação em atender às necessidades do indivíduo que leva a um esgotamento tanto físico quanto emocional (Benevides, 2002). É provável que atuar em um ambiente com pouco conforto físico potencialize riscos para o desencadeamento da síndrome.

Contudo, considerando tratar-se de um fenômeno de menor frequência de ocorrência, pesquisas previamente planejadas ou de caráter experimental são complexas para serem desenvolvidas, sendo esta uma limitação da pesquisa por ter sido analisadas apenas as evidências existentes.

\section{REFERÊNCIAS}

Bardin, L. (2011). Análise de conteúdo. São Paulo: Edições 70.

Becker, H. Métodos de pesquisa em ciências sociais. São Paulo: Hucitec, 1987. 178p.

Benevides, A. M. T. P. (2002). Burnout: quando o trabalho ameaça o bem estar do trabalhador. São Paulo: Casa do Psicólogo.

Bernstrøm, V. H.; Lone, J. A.; Bjørkli, C. A.; Ulleberg, P. \& Hoff, T. (2013). Assessing a Norwegian translation of the organizational climate measure. Psychological Reports: Human Research and Marketing, 112(2), 390-407. 
Bispo, C. A. F. (2006). Um novo modelo de pesquisa de Clima Organizacional. Produção, $16(2), 258-273$.

Brasil. (2014). Relatório da Comissão Constituída pela Portaria n⿳0 126/2012. Brasília. Recuperado em 26 novembro, 2014, de:

http://portal.mec.gov.br/index.php?option=com_docman\&task=doc_download\&gid=12386\&1 temid $=$.

Campbell, J. P.; Dunnette, M. D.; Lawler, E. E. \& Weick, K. E. (1970). Managerial behavior, performance, and effectiveness. New York: McGraw Hill.

Colossi, N. (1991). Clima organizacional. Florianópolis: CPGA/UFSC.

Costa, M. T. P. \& Alves Filho, A. (2013). Condições de Trabalho e Motivação em Contextos do Sistema Único de Saúde - SUS. Interface, 10(1).

Costa Neto, P. L. O. (1977). Estatística. São Paulo: Edgard Blücher.

Cunha, E. G. \& Mazzilli, C. (2005). A gestão do medo: o mal como instrumento de gestão na ótica da psicodinâmica do trabalho. Revista de Gestão e Planejamento, 6(11), 32-46.

Dejours, C. (1998). A loucura do trabalho: estudo de psicopatologia do trabalho. São Paulo: Cortez - Oboré.

Dejours, C. (1999). A banalização da injustiça social. Rio de Janeiro: FGV.

Fischer, A. L.; Dutra, J. S. \& Amorim, W. A. C. (2009). Gestão de Pessoas: desafios estratégicos das organizações contemporâneas. São Paulo: Atlas.

Finger, A. P. (1993). Construindo programas acadêmicos com qualidade total. Florianópolis: IEPES.

Foucault, M. (1990). Microfísica do poder. Rio de Janeiro: Graal.

Foucault, M. (1991). Vigiar e punir: história da violência nas prisões. Rio de Janeiro: Vozes.

Garrido, A. (2005). Sociopsicologia del trabajo. Barcelona: Editorial UOC.

Gil, A. C. (1996). Como Elaborar Projetos de Pesquisa. São Paulo: Editora Atlas.

Godoy, A. S. A pesquisa qualitativa e sua utilização em administração de empresas. Revista de Administração de Empresas, São Paulo, v.35, n.4, p.65-71, jul/ago 1995b.

Godoy, A. S. Pesquisa qualitativa: tipos fundamentais. Revista de Administração de Empresas, São Paulo, v.35, n.3, p.20-29, mai/jun 1995a.

Guimarães, A. T. R. (2009). Ensaio: O Princípio da Bicicleta: revisitando a mudança organizacional. Revista Capital Científico, 7(1), 187-195. 
Haguette, T.M.F. Metodologias qualitativas na sociologia. Petrópolis, Vozes, 1987. 163p.

Hall, R. (2004). Organizações: estrutura, processos e resultados. São Paulo: Pearson Prentice Hall.

Hardy B.; Harley, B. \& Philips, N. (2004). Discourse Analysis and Content Analysis: Two Solitudes? In: Y. Herrera \& B. Braumoeller (eds). Symposium: Discourse and Content Analysis. Qualitative Methods: Newsletter of the APSA Organized Section on Qualitative Methods, 2(1), 19-22.

Hendrick, H.W. (1993). Macroergonomia: uma nova proposta para aumentar a produtividade, segurança e qualidade de vida no trabalho. Anais do Congresso LatinoAmericano de Ergonomia, Florianópolis, SC, Brasil, 2.

Koys, D. \& Decotiis, T. (1991). Inductive measures of psychological climate. Human Relations, 44, 265-285.

Lei n. 9.394, de 20, Dez, 1996 (1996). Estabelece as diretrizes e bases da educação nacional. Brasília. 1996. Recuperado em 25, Nov, 2014, de http://www.planalto.gov.br/ccivil_03/leis/19394.htm

Litwin, G. H. \& Stringer, R. A. (1968) Motivation and organizational climate. Cambridge: Harvard University Press.

Luz, R. (2003). Gestão do Clima Organizacional. Rio de Janeiro: Qualitymark.

Marconi, M. D. A. \& Lakatos, E. M. (1996). Técnicas de Pesquisa: planejamento e execução de pesquisas, amostragens e técnicas de pesquisas, elaboração, análise e interpretação de dados. São Paulo: Atlas.

Martins, M. C. F. (2008). Clima Organizacional. In: M. M. M. Siqueira (Org.). Medidas do Comportamento Organizacional. Porto Alegre: Artmed.

Patterson, M. G.; West, M. A.; Shackleton, V. J.; Dawson, J. F.; Lawthom, R.; Maitlis, S.; Robinson, D. L. \& Wallace, A. M. (2005). Validating the organizational climate measure: links to managerial practices, productivity and innovation. Journal of Organizational Behavior, 26(4), 379-408.

Ramos, J., Peiró, J. M. \& Ripoll, P. (2001). Condiciones de trabajo y clima organizacional. In J. M. Peiró; F. Prieto (Org.). Tratado de psicología del trabajo: la actividad laboral en su contexto. Madrid: Síntesis Psicología, 37-92.

Rizzatti. G. (1995). Análise de fatores significativos do clima organizacional da UFSC: contribuição para implantação do programa de qualidade. Dissertação, Programa de Pósgraduação em Administração da Universidade Federal de Santa Catarina, Florianópolis, SC, Brasil. 
Rizzatti. G. (2002). Categorias de Análise de Clima Organizacional em Universidades Federais Brasileiras. Tese de Doutorado, Programa de Pós-graduação em Engenharia da Universidade Federal de Santa Catarina, Florianópolis, SC, Brasil.

Rodrigues, A. P. G. \& Gondim, S. G. (2013). Expressão e regulação emocional no contexto de trabalho: um estudo com servidores públicos. Revista de Administração da Mackenzie, $15(2), 38-65$.

Sbragia, R. (1983). Um estudo empírico sobre clima organizacional em instituições de pesquisa. Revista de Administração da USP, 18(2), 30-39.

Schein, E. H. (1996). Liderança e cultura organizacional, In: E. Schein. O líder do futuro. São Paulo: Editores Francês Hesselbein, Marshall Goldsmith e Richard Beckhard.

Schneider, B. \& Reichers, A. E. (1986). On the etiology of climates. Personnel Psychology, 36, 19-39.

Schneider, B.; Ehrhart, M. G. \& Macey, W. H. (2012). Organizational Climate and Culture. The Annual Review of Psychology, 64, 361-388.

Stoner, J. F. (1985). Administração. São Paulo: Prentice Hall. The Annual Review of Psychology, 64, 361-388.

Toro, F. A. (2001). El clima organizacional: perfil de empresas colombianas. Medellín: Cicel Ltda.

Thumim, F. J. \& Thumim, L. J. (2011). The Meansurement and Interpretation of Organizational Climate. The Journal of Psychology, 142(2), 93-109. 